This item was submitted to Loughborough's Research Repository by the author.

Items in Figshare are protected by copyright, with all rights reserved, unless otherwise indicated.

\title{
Oil shocks and volatility jumps
}

PLEASE CITE THE PUBLISHED VERSION

https://doi.org/10.1007/s11156-018-00788-y

PUBLISHER

(C) Springer

VERSION

AM (Accepted Manuscript)

PUBLISHER STATEMENT

This is a post-peer-review, pre-copyedit version of an article published in Review of Quantitative Finance and Accounting. The final authenticated version is available online at: https://doi.org/10.1007/s11156-018-00788-y

\section{LICENCE}

CC BY-NC-ND 4.0

\section{REPOSITORY RECORD}

Gkillas, Konstantinos, Rangan Gupta, and Mark Wohar. 2019. "Oil Shocks and Volatility Jumps". figshare. https://hdl.handle.net/2134/37192. 


\title{
Oil Shocks and Volatility Jumps
}

\begin{abstract}
In this paper, we analyse the role of oil price shocks, derived from expectations of consumers, economists, financial market, and policymakers, in predicting volatility jumps in the S\&P500 over the monthly period of 1988:01 to 2015:02, with the jumps having been computed based on daily data over the same period. Standard linear Granger causality tests fail to detect any evidence of oil shocks causing volatility jumps. But given strong evidence of nonlinearity and structural breaks between jumps and oil shocks, we next employed a nonparametric causality-in-quantiles test, as the linear model is misspecified. Using this data-driven robust approach, we were able to detect overwhelming evidence of oil shocks predicting volatility jumps in the S\&P500 over its entire conditional distribution, with the strongest effect observed at the lowest considered conditional quantile. Interestingly, the predictive ability of the four oil shocks on volatility jumps is found to be both qualitatively and quantitatively similar.
\end{abstract}

Keywords: S\&P500, Volatility Jumps, Oil Shocks. JEL Codes: C22, G10, Q02. 


\section{Introduction}

The existing literature has stressed the importance of oil price shocks in financial variables. Several studies indicate that there is a significant relationship between oil prices shocks and stock market returns and volatility (see Mohanty et al., 2011; Gupta and Wohar, 2017; Mohanty et al., 2017; and Smyth and Narayan, 2018). Since oil is an indicator of global growth, similar findings also exist in the bond market, foreign exchange market and energy market; yet, the effects of oil price shocks vary within markets (Baek and Seo, 2015). Other studies, such as that of Filis and Chatziantoniou (2014), indicate that the reaction of interest rates to an oil price shock is mostly based on the regime of monetary policy of each country. Furthermore, Shahzad et al. (2017) find that measures of uncertainty are induced by oil demand shocks, whereas treasury rates are mainly affected by oil supply shocks. Kang and Wang (2017) note that aggregate oil demand shocks and oil-marketspecific demand shocks mainly drive US economic policy uncertainty (EPU), while the impact of oil supply shocks on EPU is found to be weaker. ${ }^{1}$

Theoretically, oil shocks are known to affect the movements of stock markets through at least five different channels: stock valuation, monetary, output, fiscal and uncertainty (see Degiannakis et al. (2017) for a detailed discussion in this regard). To examine these channels empirically, one would need measures of oil shocks, which in turn, have been traditionally done using vector autoregressive models whereby the shocks are identified based on certain structural decomposition (Kilian and Park, 2009). More recently, Baumeister and Kilian (2016) suggest the use of the gap between the price of oil that was expected and its eventual outcome as a measure of an oil price shock. More importantly, these authors illustrate that the same change in oil prices may be perceived quite differently by households, policymakers, financial markets and economists, depending on how they form expectations. This could add an extra understanding of why some of the variations in the price of oil over the last 40 years were not obviously anticipated at the time. ${ }^{2}$ The idea is that the formation of expectations is determined by the extent to which oil price fluctuations are not anticipated. Nevertheless, in case accurate expectations about the future price of oil cannot be formed by households, policymakers, financial markets and economists, oil price expectation measures will be subject to error. The explanation behind this is that even in case the determinants of the price of oil can be understood, it is the prediction of these determinants which

\footnotetext{
${ }^{1}$ Generally, the impact of oil prices and volatility on macroeconomic, financial and commodities variables also ranks high in the research agenda. See Nandha and Brooks (2009), Malliaris and Malliaris (2011), Mohanty et al. (2012), Du and Zhao (2017), Wang and Ngene (2017), Ben Sita (2018), Cartwright and Riabko (2018) and Li and Paraco (2018). 2 The existing literature has located a number of possible determinants of oil price fluctuations and made great leaps recently in understanding the oil price fluctuations.
} 
proves to be very difficult in practice. Yet, even in this case, such evidence can be of utmost importance in several respects.

Given that this insight suggests different measures of oil shocks used by different agents in the economy to make their decisions, it is likely to have potentially important implications for understanding and modeling the transmission of oil price shocks to the economy, including financial markets. More specifically, the previous arguments can be found to be useful for researchers, practitioners, investors and policy makers. Some indicative examples are listed in what follows. Even though in the existing research literature there are numerous economic models and therefore several sophisticated econometric approaches to understanding the oil price fluctuations if it is impossible to foresee the upcoming evolution of oil price determinants, surprise fluctuations in the price of oil induced by unexpected changes will be unavoidable. From an econometric modelling perspective, this indicates that models studying the effects of oil price shocks on financial markets are possibly flawed and the inclusion of the measures of the expectations as determinants are necessary. Furthermore, since oil price shocks are a foremost concern for policymakers, given their well-documented ability to impact several financial variables, (see Hamilton, 2008; and Kilian and Park, 2009), the different perception of an oil price shock due to different expectations between investors and policymakers, for example, could lead to underestimation (overestimation) of a situation. Hence, ineffective policy interventions can arise. From a policy perspective, understanding the existence of different expectations and therefore different perceptions is pivotal for the required optimal reaction for stabilization, following an oil price shock.

Against this backdrop, the objective of this paper is to analyze the predictive ability of oil price shocks as perceived by households, policymakers, financial markets, and economists on volatility jumps in the S\&P500 over the monthly period of 1988:03 to 2015:02, with the jumps having been computed based on daily data over the same period. Note that financial market volatility is used as an important input in investment decisions, option pricing and financial market regulation (Poon and Granger, 2003). In light of this, financial market participants care not only about the nature of volatility, but also about its level, with all traders making the distinction between good and bad volatilities (Giot et al., 2010). Good volatility is directional, persistent and relatively easy to predict, while bad volatility is jumpy and comparatively difficult to foresee. Therefore, good volatility is generally associated with the continuous and persistent part, while bad volatility captures the discontinuous and jump component of volatility.

In fact, volatility jumps constitute an additional source of non-diversifiable risk in volatility, which is locally sourced and more difficult to predict. Thus, the incorporation of jumps is required 
for asset allocation and risk management (Wu, 2003). The jump diffusion models form an important tool for option pricing and account for stock price fluctuations and market risks adequately (Psychoyios et al., 2010; Mozumder et al., 2012; Lin et al., 2018). Given this, jumps help to forecast equity risk premium (Santa-Clara and Yan, 2010), variance risk premium (Li and Zinna, 2014) and returns (Andersen et al., 2015). What is more, it has been stressed that modeling jumps can improve the overall fit of volatility models (Duffie et al., 2000; Eraker et al., 2003; Broadie et al., 2007; Chang et al., 2007; Todorov and Tauchen, 2011). Understandably, a large literature has developed trying to not only model jumps, but also explain the causes behind such jumps based on financial variables (Caporin et al., 2016), and news based on text-search (Cutler et al., 1989; Boudoukh et al., 2015; Baker et al., 2015; Gkillas et al., 2018). With an already large number of studies investigating the impact of oil shocks on stock market returns and volatility, our paper departs from this line of research and aims to add to the literature on the drivers of volatility jumps by analysing for the first time, the predictive ability of oil price shocks as perceived by various agents in the economy.

For our predictability analysis, we rely on the nonparametric causality-in-quantiles test of Jeong et al., (2012), and hence, in the process of capturing various phases (sizes) of volatility jumps. Understandably, the causality-in-quantiles test used here is inherently a time-varying approach as various parts of the conditional distribution of volatility jumps would relate to various points in time associated with the evolution of jumps. The causality-in-quantile approach has the following two main novelties: First, it is robust to misspecification errors as it detects the underlying dependence structure between the examined time series. This is particularly important as we show that volatility jumps are nonlinearly associated with the oil shocks - a result that should not come as a surprise, in that there is ample evidence of financial market variables being nonlinearly related to their predictors, including oil shocks (Jiménez-Rodríguez, 2015). And second, using this methodology, we are able to test not only for causality-in-mean (1st moment) (see for example, Heimstra and Jones, 1994; Diks and Panchenko, 2005, 2006), but also for causality that may exist in the tails of the joint distribution of the variables. This is again of tremendous importance since our dependent variable, i.e., volatility jumps, are shown to have fat-tails - a feature also outlined in Bollerslev et al., (2013).

Our study has important implications for practitioners (i.e. asset managers and risk managers) and policymakers. Our main target is to understand more efficiently the nature of jumpy volatility, due to oil price shocks generating from different expectation mechanisms. This is expected to have various consequences for volatility modelling. This understanding is important for developing hedging strategies and specification of market risk premia. Primarily, investors 
make their investment decisions associated with risk management and designing an appropriate asset allocation strategy. However, their decision behaviour can be changed by their subjective perception on the arrival of new information related to oil price shocks due to different expectations. Different decisions can lead to short (or long) to bullishness or bearishness and thus can affect the expected risk premia. ${ }^{3}$ In particular, if jumps originate from different expectation generating mechanisms, due to oil price shocks, then hedging strategies should be put into a new context and a common hedging may not work efficiently. A separate hedging may be more appropriate, targeting mainly in different financial sectors which can be affected quite differently by different expectations for the same event. Given that oil is a major production factor, different expectations from oil price shocks are anticipated to have a different impact on consumer and business spending, inflation and the real interest rate, and therefore, they are expected to affect differentially the most closely related financial sectors. Additionally, jump risks may not be spanned with commonly traded derivative products, and consequently, more targeted derivates could be more effective. Furthermore, on a macro level, our study has various implications for the risk premia associated with jump risk and therefore with volatility risk. If jump size risk is different, due to different expectations for the same risk, then jump risk premia share compensations should be modeled separately. Finally, considering that policymakers have to make decisions during periods of jump-inducing turbulence in financial markets, it is economically vital to progress an econometric understanding of the time series behaviour of jumps in accordance with their real generating mechanism (see Todorov and Tauchen, 2011).

The remainder of the paper is organized as follows: Section 2 lays out the basics of the econometric methodologies involving volatility jumps and the causality-in-quantiles approach. Section 3 presents the data and results, with Section 4 concluding the paper.

\section{Econometric Methodologies}

\subsection{Volatility Jumps}

We employ daily $\log$ returns $R_{t, i}$ of the S\&P500 to estimate the monthly median realized variance $\left(M R V_{t}\right)$. In each month $t$, we retrieve a monthly point estimate of the $M R V_{t}$ by employing all daily returns. We calculate monthly volatility by the median realized variance, $M R V_{t}$, which attenuates the effect of noise, as introduced by Andersen et al. (2012), as follows:

\footnotetext{
3 Sariannidis et al. (2016) claim that lower oil prices decrease the perception of related risk among investors. Furthermore, Ding et al. (2017) show that there is significant causality from oil price fluctuations to stock market investor sentiment, stressing major changes in the impact between the short term and the long term.
} 
$M R V_{t}=\gamma\left(\frac{N}{N-2}\right) \sum_{i=1}^{N-1} \operatorname{med}\left(\left|R_{t, i-1}\right|,\left|R_{t, i}\right|,\left|R_{t, i+1}\right|\right)^{2}$

where, $\gamma=\left(\frac{\pi}{6-4 \sqrt{3}+\pi}\right), R_{t, i}$ is the daily return for day $i$ within month $t$ and $i=1, \ldots N$, where $N$ is the total number of daily observations within a month.

Following Bekaert and Hoerova (2014), we employ the threshold bipower variation $\left(T B P V_{t}\right)$ as a jump-free volatility estimator as defined in Corsi et al. (2010), as follows:

$T B P V_{t}=\sum_{i=2}^{N}\left|R_{t, i-1}\right|,\left|R_{t, i}\right| I_{\left\{\left|R_{t, i-1}\right|^{2} \leq \theta_{i-1}\right\}} I_{\left\{\left|R_{t, i}\right|^{2} \leq \theta_{i}\right\}}$

where $I_{\{\cdot\}}$ is the indicator function and the threshold function, $R_{t, i}$ is the daily return series and $t$ represents the time in months.

Then, we calculate the jump statistic $\left(Z J_{t}^{(T B P V)}\right)$ following Duong and Swanson (2015), as follows:

$Z J_{t}^{(T B P V)}=\sqrt{N} \frac{\left(M R V_{t}-T B P V_{t}\right) M R V_{t}^{-1}}{\left[\left(\xi_{1}^{-4}+2 \xi_{1}^{-2}-5\right) \max \left\{1, T Q_{t} T B P V_{t}^{-2}\right\}\right]^{1 / 2}}$

where $T Q_{t}$ is the realized tripower quarticity which is $T Q_{t}=$ $N \xi_{4 / 3}^{-3} \sum_{i=1}^{N}\left|R_{t, i}\right|^{4 / 3}\left|R_{t, i+1}\right|^{4 / 3}\left|R_{t, i+2}\right|^{4 / 3}$ and converges in probability to integrated quarticity. The $Z J_{t}^{(T B P V)}$ statistic follows a normal gaussian distribution.

A jump is considered to be significant if the $Z J_{t}^{(T B P V)}$ exceeds the appropriate critical value of the standard gaussian distribution, denoted by $\Phi_{a}$, at a $a$ significant level. The jump component of volatility in monthly frequency is:

$J U M P_{t}^{(T B P V)}=\left|M R V_{t}-T B P V_{t}\right| I_{\left\{Z J_{t}^{(T B P V)}>\Phi_{a}\right\}}$

where $I_{\{\cdot\}}$ represents an indicator function of the $Z J_{t}^{(T B P V)}$ exceeds of a given critical value of a Gaussian distribution.

\subsection{Causality-in-Quantiles}

This sub-section provides a brief description of the quantile-based methodology based on the framework of Jeong et al. (2012). As mentioned earlier, this approach is robust to extreme values in the data and captures general nonlinear dynamic dependencies. Let $y_{t}$ denote volatility jumps and $x_{t}$ denote the predictor variable, in our case the various oil price shocks, considered in turn as perceived by households, policymakers, financial markets, and economists (discussed in detail in the Data segment of the paper). 
Formally, let $Y_{t-1} \equiv\left(y_{t-1}, \ldots, y_{t-p}\right), \quad X_{t-1} \equiv\left(x_{t-1}, \ldots, x_{t-p}\right), \quad Z_{t}=\left(Y_{t}, X_{t}\right)$ and $F_{y_{t \mid Z_{t-1}}}\left(y_{t}, Z_{t-1}\right)$ and $F_{y_{t \mid Y} Y_{t-1}}\left(y_{t}, Y_{t-1}\right)$ denote the conditional distribution functions of $y_{t}$ given $Z_{t-1}$ and $Y_{t-1}$, respectively. If we denote $Q_{\theta}\left(Z_{t-1}\right) \equiv Q_{\theta}\left(y_{t} \mid Z_{t-1}\right)$ and $Q_{\theta}\left(Y_{t-1}\right) \equiv$ $Q_{\theta}\left(y_{t} \mid Y_{t-1}\right)$, we have $F_{y_{t \mid Z_{t-1}}}\left\{Q_{\theta}\left(Z_{t-1}\right) \mid Z_{t-1}\right\}=\theta$ with probability one. Consequently, the (non)causality in the $\theta^{\text {th }}$ quantile hypotheses to be tested can be specified as:

$H_{0}: P\left\{F_{y_{t \mid Z_{t-1}}}\left\{Q_{\theta}\left(Y_{t-1}\right) \mid Z_{t-1}\right\}=\theta\right\}=1$

$H_{1}: P\left\{F_{y_{t \mid Z_{t-1}}}\left\{Q_{\theta}\left(Y_{t-1}\right) \mid Z_{t-1}\right\}=\theta\right\}<1$.

Jeong et al. (2012) employ the distance measure $J=\left\{\varepsilon_{t} E\left(\varepsilon_{t} \mid Z_{t-1}\right) f_{z}\left(Z_{t-1}\right)\right\}$, where $\varepsilon_{t}$ is the regression error term and $f_{z}\left(Z_{t-1}\right)$ is the marginal density function of $Z_{t-1}$. The regression error $\varepsilon_{t}$ emerges based on the null hypothesis in (5), which can only be true if and only if $E\left[1\left\{y_{t} \leq Q_{\theta}\left(Y_{t-1}\right) \mid Z_{t-1}\right\}\right]=\theta$ or, equivalently, $1\left\{y_{t} \leq Q_{\theta}\left(Y_{t-1}\right)\right\}=\theta+\varepsilon_{t}$, where $1\{\cdot\}$ is an indicator function. Jeong et al. (2012) show that the feasible kernel-based sample analogue of $J$ has the following form:

$\hat{J}_{T}=\frac{1}{T(T-1) h^{2 p}} \sum_{t=p+1}^{T} \sum_{s=p+1, S \neq t}^{T} K\left(\frac{Z_{t-1}-Z_{s-1}}{h}\right) \hat{\varepsilon}_{t} \hat{\varepsilon}_{s}$

where $K(\cdot)$ is the kernel function with bandwidth $h, T$ is the sample size, $p$ is the lag order, and $\hat{\varepsilon}_{t}$ is the estimate of the unknown regression error, which is estimated as follows:

$\hat{\varepsilon}_{t}=1\left\{y_{t} \leq Q_{\theta}\left(Y_{t-1}\right)\right\}-\theta$.

$\widehat{Q}_{\theta}\left(Y_{t-1}\right)$ is an estimate of the $\theta^{t h}$ conditional quantile of $y_{t}$ given $Y_{t-1}$, and we estimate $\widehat{Q}_{\theta}\left(Y_{t-1}\right)$ using the nonparametric kernel method as:

$\widehat{Q}_{\theta}\left(Y_{t-1}\right)=\hat{F}_{y_{t \mid Y_{t-1}}^{-1}}\left(\theta \mid Y_{t-1}\right)$

where $\hat{F}_{\left.y_{t \mid Y}\right|_{t-1}}\left(y_{t} \mid Y_{t-1}\right)$ is the Nadarya-Watson kernel estimator given by:

$\widehat{F}_{y_{t \mid Y_{t-1}}}\left(y_{t} \mid Y_{t-1}\right)=\frac{\sum_{s=p+1, s \neq t}^{T} L\left(\frac{\left(Y_{t-1}-Y_{s-1}\right)}{h}\right) 1\left(y_{s} \leq y_{t}\right)}{\sum_{s=p+1, s \neq t}^{T} L\left(\frac{\left(Y_{t-1}-Y_{s-1}\right)}{h}\right)}$

with $L(\cdot)$ denoting the kernel function and $h$ the bandwidth.

The empirical implementation of causality testing via quantiles entails specifying three important choices: the bandwidth $h$, the lag order $p$ and the kernel type for $K(\cdot)$ and $L(\cdot)$ respectively. In this study, we use $p=1$ based on the Schwarz Information Criterion (SIC). Note that, when it comes to choosing lags, the SIC is considered to be parsimonious compared to other lag-length selection criteria. The SIC helps overcome the issue of over-parameterization usually 
arising with nonparametric frameworks. The bandwidth value is chosen by employing the least squares cross-validation techniques. ${ }^{4}$ Finally, for $K(\cdot)$ and $L(\cdot)$, Gaussian-type kernels were employed.

\section{Data and Results}

\subsection{Data}

Monthly data on oil price shocks is based on the work of Baumeister and Kilian (2016) on oil price expectations of consumers, policymakers, financial market and consumers. ${ }^{5}$ These authors employ a VAR model specification that includes the real price of oil, global crude oil production, global real economic activity and changes in global crude oil stocks, and refer to the implied expectation of the price of oil as the economists' expectation. The most common approach to inferring the expected price of oil for immediate delivery in the physical market (also known as the spot price). The convention has been to treat the price of the oil futures contract with maturity $h$ as the $b$ period ahead market expectation of the nominal price of crude oil, which in turn is used as the measure of the policymakers' oil price expectation by Baumeister and Kilian (2016). Recently, Hamilton and $\mathrm{Wu}$ (2014) document that there is a large horizon-specific time-varying risk premium in the oil futures market. Furthermore, this risk premium is shown to vary with the hedging demands of oil producers and refiners and the willingness of financial investors to take the other side of hedging contracts. Baumeister and Kilian (2016) then recover the oil price expectation of financial market by subtracting Hamilton and Wu's (2014) estimates of the risk premium from the oil futures price for a given horizon. Finally, Baumeister and Kilian (2016) assume that consumers forecast the real and nominal prices of crude oil according to a simple no-change model such that the nominal price is expected to grow at the rate of inflation. This allows them to proxy consumer expectations about the nominal price of oil based on the current price of oil and an inflation forecast based on the Michigan Survey of Consumers about the price of gasoline (primarily determined by the price of crude oil) and inflation. Once these expectations are derived, we, as in Baumeister and Kilian (2016), compute the corresponding perception of oil price shocks by subtracting these expectations from the realized (actual) West Texas Intermediate (WTI) spot price of that month, with the WTI oil data obtained from the FRED database of the Federal Reserve Bank of St. Louis.

As indicated above in Subsection 2.1, we use daily returns of the S\&P500 to arrive at the monthly volatility jump values. Stock returns are computed as the logarithmic first difference of

\footnotetext{
${ }^{4}$ For each quantile, we determine the bandwidth $h$ using the leave-one-out least-squares cross validation method of Racine and Li (2004) and Li and Racine (2004).

${ }^{5}$ We would like to thank Professor Christiane Baumeister for kindly providing us with this data.
} 
the daily S\&P500 stock price index, with data on the S\&P500 stock index obtained from Datastream of Thomson Reuters. Note that our analysis covers the monthly period from 1988:03 to 2015:02 (i.e., 324 months), with the start and end date being purely driven by the availability of data on the oil price expectations. Figures A1(a) and A1(b) in the Appendix plot the volatility jump variable and the oil price shocks respectively, while Table A1 reports the summary statistics of the variables under consideration. The summary statistics highlight how different the various oil price shocks are from each other. While volatility in general is quite close to each other, with economists' oil price shocks having the highest volatility and consumers' version of the same the lowest, the mean values are quite different. The financial market and consumers' oil price shocks have positive means, but for the policymakers' and economists' oil price shocks, the means are negative. While excess kurtosis is observed for all the four oil shocks as well as for volatility jumps (JUMPS), negative skewness is observed for policymakers' and consumers' oil price shocks. More importantly, all the variables have non-normal distributions, as indicated by the overwhelming rejection (at 1 percent level of significance) of the null of normality under the Jarque-Bera test. The heavy-tail of the unconditional distribution of volatility jumps provides a preliminary justification for the causality-in-quantiles test used in the empirical analysis.

\section{[INSERT FIGURE A1 and TABLE A1]}

\subsection{Empirical Findings}

Before we discuss the findings from the causality-in-quantiles test, for the sake of completeness and comparability, we first conducted the standard linear Granger causality test, with a lag-length of one, as determined by the SIC. The resulting $\chi^{2}(1)$ statistics, as reported in Table 1 , suggests that the null that the various oil price shocks (consumers', economists', financial market, and policymakers') does not Granger cause JUMPS, cannot be rejected even at the 10 percent level of significance. Therefore, based on the standard linear test, one would conclude no significant oil shocks-related effects on S\&P500 volatility jumps.

\section{[INSERT TABLE 1]}

Given the insignificant results obtained from the linear causality tests, we next statistically examine the presence of nonlinearity and structural breaks in the relationship between volatility jumps and the four oil shocks. Nonlinearity and regime changes, if present, would further motivate the use of the nonparametric quantiles-in-causality approach, as the quantiles-based test would formally address nonlinearity and structural breaks in the relationship between the two variables under investigation. For this purpose, we apply the Brock et al., (1996, BDS) test on the residuals from the jump equation involving one lag of JUMPS and a specific oil shock. Table 2 presents the 
results of the BDS test of nonlinearity. As shown in this table, we find strong evidence, at highest level of significance, for the rejection of the null of i.i.d. residuals at various embedded dimensions $(m)$, which in turn is indicative of nonlinearity in the relationship between JUMPS and the four oil shocks considered in turn. To further motivate the causality-in-quantiles approach, we next used the powerful UDmax and WDmax tests of Bai and Perron (2003) to detect 1 to $M$ structural breaks in the relationship between JUMPS and the oil shocks, allowing for heterogenous error distributions across the breaks. When we applied these tests again to the jump equation involving one lag of JUMPS and a particular oil shock under consideration, we detected two breaks each for the economists', financial markets' and policymakers' oil price shocks in months 2004:12 and 2008:12, while only one break was found under the case of the consumers' oil price shock in 20018:11. Note that, while the early break date corresponds to sharp increases, the latter is associated with a decline in the oil price, as well as a sharp increase in volatility jumps in the wake of the global financial crisis. These finding indicate that the results based on the linear Granger causality test cannot be deemed robust and reliable.

\section{[INSERT TABLE 2]}

Given the strong evidence of nonlinearity and structural break(s) in the relationship between volatility jumps and oil shocks, we now turn our attention to the causality-in-quantiles test, which is robust to linear misspecification due to its nonparametric (i.e., data-driven) approach. As can be seen from Figure 1, which reports this test for the quantile range of 0.05 to 0.95, the null that the four oil shocks (considered sequentially) does not Granger causes JUMPS is overwhelmingly rejected at the 5 percent level of significance (given the critical value of 1.96), with the strongest evidence of predictability observed at the lowest quantile of the conditional distribution of JUMPS. Note that, to study which of these oil shocks has a stronger impact on JUMPS, we standardized the oil shocks by dividing with their respective standard deviation. Interestingly, the strength of causality is found to be quite similar across the four oil shocks considered. But more importantly, our results highlight that when we account for nonlinearity and structural breaks using a nonparametric approach, we are able to find strong evidence of predictability emanating from oil shocks into volatility jumps of the S\&P500, unlike what was observed under the linear framework. To put it alternatively, we observe that oil shocks can predict volatility jumps of the S\&P500, irrespective of the magnitude of the jumps, as captured by the various quantiles of the conditional distribution of JUMPS.

\section{[INSERT FIGURE 1]}

To get additional insights into the results obtained, we conducted three additional analyses and report them in the Appendix of the paper. First, we repeat our analysis using the cross- 
quantilogram approach of Han et al. (2016). The cross-quantilogram measures quantile dependence and tests for directional predictability between two time series. ${ }^{6}$ Using this approach, as reported in Figure A2(a)-(h), we observe that oil shocks do positively and significantly affect volatility jumps, with this effect being particularly strong at higher quantiles, i.e., for higher magnitude of the various oil price shocks. In other words, in line with the extant literature on the asymmetric effect of oil price shocks on stock markets (see for example the discussion in Alsalman and Herrera, 2015), larger shocks tend to cause bigger volatility jumps. Second, just as there is a large literature on the size of the oil shock, there are also many studies that have looked into the effect of the sign of shock, i.e., whether an oil shock is positive or negative (see for example, Narayan and Gupta (2015) for a detailed review). Given this, we decompose the various oil shocks into their positive and negative components by first defining two dummy variables, which take a value of 1 when the shock is positive and 0 otherwise and vice-versa (i.e., 1 when the shock is negative and 0 otherwise), and then we multiply these two dummy variables with the oil price shocks separately to obtain the positive and negative oil shocks for each of the four agents. As can be seen from Table A2, while the strongest predictability is observed at the lowest conditional quantile of JUMPS, there is hardly any evidence in favour of causality beyond the conditional median. This result tends to suggest that, disaggregating the oil shocks into its positive and negative components is not necessarily of value when it comes to predicting volatility jumps of the S\&P500, as unlike the overall shocks, the predictability gets restricted to smaller volatility jumps only. Finally, we revisit our analysis by computing oil shocks at various horizons based on the financial market expectations of oil price at various horizons (3-, 6-, 9-, and 12-month-ahead), as recently developed by Baumeister and Kilian (2017). ${ }^{7}$ Our results derived in the main text carries over to this measure of financial market's oil price shock, as we observe from Table A3 that, irrespective of the horizon considered, the effect is strongest at the lower quantiles of JUMPS. One interesting observation is that at the longest-horizon of 12-month-ahead, oil price shocks, unlike at horizons of 3-, 6- and 9-month-ahead, fail to predict volatility jumps beyond the conditional quantile of 0.40. In other words, the predictive content of the oil price shock at the horizon considered is absent when it comes to explaining large volatility jumps. However, just in the case of positive financial market's oil shocks based on the Baumeister and Kilian's (2016) data discussed above in the second point, the effect is restricted only at the lower quantiles of the conditional distribution of JUMPS. But contrary to what was discussed earlier under the second issue above, for the

\footnotetext{
6 The reader is referred to Han et al. (2016) for further details on the technical details of the cross-quantilogram methodology.

7 The data is available for download from the website of Professor Christiane Baumeister at: https://sites.google.com/site/cjsbaumeister/research, and covers the monthly period of 1992:01 to 2017:06
} 
negative version of these financial market oil price shocks at various horizons, predictability is observed at certain moderately high quantiles excluding the region around the median, even for the 12-month-ahead horizon. This result tends to hint towards the fact that larger volatility jumps are likely to be driven by negative oil price shocks perceived by the financial market.

\section{[INSERT FIGURE A2 and TABLES A2 AND A3]}

\section{Conclusions}

In the recent volatility-related literature, it has been stressed that jumps in volatility can improve the overall fit of volatility models. Therefore, a large literature has developed trying to not only model volatility jumps, but also attempting to explain the causes behind such jumps based on financial variables, and more recently, news. Given this, in this paper, we analyse the role of oil price shocks derived from expectations of consumers, economists, financial market, and policymakers, in predicting volatility jumps in the S\&P500 over the monthly period from 1988:01 to 2015:02, with the jumps having been computed based on daily data over the same period. For our predictability analysis, we rely on a nonparametric causality-in-quantiles test, which in turn is robust to misspecification due to nonlinearity and structural breaks being a data-driven procedure.

Starting off with the standard linear causality test, we were unable to detect any evidence of oil shocks causing volatility jumps. But, we indicate that linear Granger causality test results cannot be relied upon because formal tests reveal strong evidence of nonlinearity and structural breaks between volatility jumps and the four different oil shocks. Hence, linear Granger causality tests are misspecified. When we used the nonparametric causality-in-quantiles test instead, we were able to detect overwhelming evidence rejecting the null hypothesis that oil shocks do not Granger cause jumps over the entire conditional distribution of the latter, with the strongest effect observed at the lowest considered conditional quantile. Interestingly however, even though the underlying nature of the oil shocks is quite different, the effects of the four oil shocks considered are found to be both qualitatively and quantitatively similar in predicting the S\&P500 volatility jumps. Thus, our results indicated that when we control for misspecification due to nonlinearity and regime changes, it is indeed true that oil shocks can predict movements in volatility jumps of the S\&P500, irrespective of the size of such jumps. Interestingly however, the strength of causality is found to be quite similar across the four oil shocks considered.

Though there exists a large literature on the effect of oil shocks on returns and volatility of equity markets, which motivated us to concentrate only on volatility jumps, as part of future research it would be interesting to revisit the effect of these newly identified shocks as perceived by various agents on stock returns and volatility. In addition, it would be particularly interesting to 
expand our study to the sector indices of the S\&P 500 so us to see if specific sectors are more sensitive to expectations of households, policymakers, financial markets and economists in oil price shocks. Finally, one could also analyze the role of these oil shocks on volatility jumps of equity markets of other developed and developing countries, besides alternative asset classes, such as currencies, bonds and commodities. 


\section{References}

Alsalman Ana María Herrera Z (2015) Oil Price Shocks and the U.S. Stock Market: Do Sign and Size Matter? Energy J 36:171-189. doi: 10.5547/01956574.36.3.7

Andersen TG, Dobrev D, Schaumburg E (2012) Jump-robust volatility estimation using nearest neighbor truncation. In: Journal of Econometrics. North-Holland, pp 75-93

Andersen TG, Fusari N, Todorov V (2015) The risk premia embedded in index options. J financ econ 117:558-584. doi: 10.1016/j.jfineco.2015.06.005

Baek J, Seo J-Y (2015) A Study on Unobserved Structural Innovations of Oil Price: Evidence from Global Stock, Bond, Foreign Exchange, and Energy Markets. Rev Pacific Basin Financ Mark Policies 18:1550004. doi: 10.1142/S0219091515500046

Bai J, Perron P (2003) Computation and analysis of multiple structural change models. J Appl Econom 18:1-22. doi: 10.1002/jae.659

Baker SR, Bloom N, Davis SJ (2016) Measuring Economic Policy Uncertainty.

Baker SR, Bloom N, Davis S (2015) What triggers stock market jumps? In: Work in progress presented at the January 2015 ASSA meetings.

Baumeister C, Kilian L (2016) Forty Years of Oil Price Fluctuations: Why the Price of Oil May Still Surprise Us. J Econ Perspect 30:139-160. doi: 10.1257/jep.30.1.139

Baumeister C, Kilian L (2017) A General Approach to Recovering Market Expectations from Futures Prices with an Application to Crude Oil.

Bekaert G, Hoerova M (2014) The VIX, the variance premium and stock market volatility. J Econom 183:181-190. doi: 10.1016/j.jeconom.2014.05.008

Ben Sita B (2018) Crude oil and gasoline volatility risk into a Realized-EGARCH model. Rev. Quant. Financ. Account. 1-20.

Bollerslev T, Todorov V, Li SZ (2013) Jump tails, extreme dependencies, and the distribution of stock returns. In: Journal of Econometrics. pp 307-324

Boudoukh J, Feldman R, Kogan S, Richardson M (2015) News and Stock Prices: New Insights.

Broadie M, Chernov M, Johannes M (2007) Model specification and risk premia: Evidence from futures options. J Finance 62:1453-1490. doi: 10.1111/j.1540-6261.2007.01241.x

Broock WA, Scheinkman JA, Dechert WD, LeBaron B (1996) A test for independence based on the correlation dimension. Econom Rev 15:197-235. doi: 10.1080/07474939608800353

Caporin M, Rossi E, De Magistris PS (2015) Volatility jumps and their economic determinants. J Financ Econom 14:29-80. doi: 10.1093/jjfinec/nbu028

Cartwright PA, Riabko N (2018) Do spot food commodity and oil prices predict futures prices? Rev. Quant. Financ. Account. 1-42.

Chang J-R, Hung M-W, Lee C-F, Lu H-M (2007) The Jump Behavior of Foreign Exchange Market: Analysis of Thai Baht. Rev Pacific Basin Financ Mark Policies 10:265-288. doi: 10.1142/S0219091507001069

Corsi F, Pirino D, Renò R (2010) Threshold bipower variation and the impact of jumps on volatility forecasting. J Econom 159:276-288. doi: 10.1016/j.jeconom.2010.07.008

Cutler DM, Poterba JM, Summers LH (1989) What moves stock prices? J Portf Manag 15:4-12. doi: $10.3905 /$ jpm.1989.409212 
Diks C, Panchenko V (2005) A Note on the Hiemstra-Jones Test for Granger Non-causality. Stud Nonlinear Dyn Econom. doi: 10.2202/1558-3708.1234

Diks C, Panchenko V (2006) A new statistic and practical guidelines for nonparametric Granger causality testing. J Econ Dyn Control 30:1647-1669. doi: 10.1016/j.jedc.2005.08.008

Ding Z, Liu Z, Zhang Y, Long R (2017) The contagion effect of international crude oil price fluctuations on Chinese stock market investor sentiment. Appl Energy 187:27-36. doi: 10.1016/j.apenergy.2016.11.037

Du D, Zhao X (2017) Financial investor sentiment and the boom/bust in oil prices during 20032008. Rev Quant Financ Account 48:331-361. doi: 10.1007/s11156-016-0553-5

Duffie D, Pan J, Singleton K (2000) Transform Analysis and Asset Pricing for Affine Jumpdiffusions. Econometrica 68:1343-1376. doi: 10.1111/1468-0262.00164

Duong D, Swanson NR (2015) Empirical evidence on the importance of aggregation, asymmetry, and jumps for volatility prediction. J Econom 187:606-621. doi: 10.1016/j.jeconom.2015.02.042

Eraker B, Johannes M, Polson N (2003) The Impact of Jumps in Volatility and Returns. J Finance 58:1269-1300. doi: 10.1111/1540-6261.00566

Filis G, Chatziantoniou I (2014) Financial and monetary policy responses to oil price shocks: Evidence from oil-importing and oil-exporting countries. Rev Quant Financ Account 42:709-729. doi: 10.1007/s11156-013-0359-7

Giot P, Laurent S, Petitjean M (2010) Trading activity, realized volatility and jumps. J Empir Financ 17:168-175. doi: 10.1016/j.jempfin.2009.07.001

Gkillas K, Gupta R, Wohar ME (2018) Volatility jumps: The role of geopolitical risks. Financ. Res. Lett.

Gupta R, Wohar M (2017) Forecasting oil and stock returns with a Qual VAR using over 150 years off data. Energy Econ 62:181-186. doi: 10.1016/j.eneco.2017.01.001

Hamilton J (2008) Understanding Crude Oil Prices. Cambridge, MA. NBER. doi:10.3386/w14492

Hamilton JD (2015) Causes and Consequences of the Oil Shock of 2007-08. Cambridge, MA. NBER. doi:10.2139/ssrn.2583456

Hamilton JD, Wu JC (2014) Risk premia in crude oil futures prices. J Int Money Financ 42:9-37. doi: 10.1016/j.jimonfin.2013.08.003

Han H, Linton O, Oka T, Whang YJ (2016) The cross-quantilogram: Measuring quantile dependence and testing directional predictability between time series. J Econom 193:251270. doi: 10.1016/j.jeconom.2016.03.001

Hiemstra C, Jones JD (1994) Testing for Linear and Nonlinear Granger Causality in the Stock Price-Volume Relation. J Finance 49:1639-1664. doi: 10.1111/j.1540-6261.1994.tb04776.x

Hurvich CM, Tsai C-L (1989) Regression and time series model selection in small samples. Biometrika 76:297-307. doi: 10.1093/biomet/76.2.297

Jeong K, Härdle WK, Song S (2012) A consistent nonparametric test for causality in quantile. Econom Theory 28:861-887. doi: 10.1017/S0266466611000685

Jiménez-Rodríguez R (2015) Oil price shocks and stock markets: testing for non-linearity. Empir Econ 48:1079-1102. doi: 10.1007/s00181-014-0832-8

Kang W, Wang J (2018) Oil shocks, policy uncertainty and earnings surprises. Rev Quant Financ Account 51:375-388. doi: 10.1007/s11156-017-0674-5 
Kilian L, Park C (2009) The Impact of Oil Price Shocks on the U.S. Stock Market. Int Econ Rev (Philadelphia) 50:1267-1287. doi: 10.1111/j.1468-2354.2009.00568.x

Li H, Paraco R (2018) Impact of Oil Price on Australian Stock Market Returns. Rev Pacific Basin Financ Mark Policies 21:1850018. doi: 10.1142/S0219091518500182

Li J, Zinna G (2018) The Variance Risk Premium: Components, Term Structures, and Stock Return Predictability. J Bus Econ Stat 36:411-425. doi: 10.1080/07350015.2016.1191502

Li Q, Racine J (2004) Cross-validated local linear nonparametric regression. Stat. Sin. 14:485-512.

Lin CH, Lin SK, Wu AC (2015) Foreign exchange option pricing in the currency cycle with jump risks. Rev Quant Financ Account 44:755-789. doi: 10.1007/s11156-013-0425-1

Malliaris AG, Malliaris M (2013) Are oil, gold and the euro inter-related? Time series and neural network analysis. Rev Quant Financ Account 40:1-14. doi: 10.1007/s11156-011-0265-9

Mohanty SK, Akhigbe A, Al-Khyal TA, Bugshan T (2013) Oil and stock market activity when prices go up and down: The case of the oil and gas industry. Rev Quant Financ Account 41:253-272. doi: 10.1007/s11156-012-0309-9

Mohanty SK, Nandha M (2011) Oil Shocks and Equity Returns: An Empirical Analysis of the US Transportation Sector. Rev Pacific Basin Financ Mark Policies 14:101-128. doi: 10.1142/S0219091511002159

Mohanty SK, Onochie J, Alshehri AF (2018) Asymmetric effects of oil shocks on stock market returns in Saudi Arabia: evidence from industry level analysis. Rev Quant Financ Account 51:595-619. doi: 10.1007/s11156-017-0682-5

Mozumder S, Sorwar G, Dowd K (2013) Option pricing under non-normality: A comparative analysis. Rev Quant Financ Account 40:273-292. doi: 10.1007/s11156-011-0271-y

Nandha M, Brooks R (2009) Oil prices and transport sector returns: An international analysis. Rev Quant Financ Account 33:393-409. doi: 10.1007/s11156-009-0120-4

Narayan PK, Gupta R (2015) Has oil price predicted stock returns for over a century? Energy Econ 48:18-23. doi: 10.1016/J.ENECO.2014.11.018

Poon S-H, Granger CWJ (2003) Forecasting Volatility in Financial Markets: A Review. J Econ Lit 41:478-539. doi: 10.1257/002205103765762743

Psychoyios D, Dotsis G, Markellos RN (2010) A jump diffusion model for VIX volatility options and futures. Rev Quant Financ Account 35:245-269. doi: 10.1007/s11156-009-0153-8

Racine J, Li Q (2004) Nonparametric estimation of regression functions with both categorical and continuous data. J Econom 119:99-130. doi: 10.1016/S0304-4076(03)00157-X

Santa-Clara P, Yan S (2010) Crashes, volatility, and the equity premium: Lessons from S\&P 500 options. Rev Econ Stat 92:435-451. doi: 10.1162/rest.2010.11549

Sariannidis N, Giannarakis G, Zafeiriou E, Billias I (2016) The effect of crude oil price moments on socially responsible firms in Eurozone. Int J Energy Econ Policy 6:356-363.

Shahzad SJH, Bouri E, Raza N, Roubaud D (2018) Asymmetric impacts of disaggregated oil price shocks on uncertainties and investor sentiment. Rev. Quant. Financ. Account. 1-21.

Smyth R, Narayan PK (2018) What do we know about oil prices and stock returns? Int Rev Financ Anal 57:148-156. doi: 10.1016/j.irfa.2018.03.010

Todorov V, Tauchen G (2011) Volatility jumps. J Bus Econ Stat 29:356-371. doi: $10.1198 /$ jbes. 2010.08342 
Wang J, Ngene G (2018) Symmetric and asymmetric nonlinear causalities between oil prices and the U.S. economic sectors. Rev Quant Financ Account 51:199-218. doi: 10.1007/s11156017-0668-3

Wu L (2003) Jumps and dynamic asset allocation. Rev Quant Financ Account 20:207-243. doi: 10.1023/A:1023699711805 
Table 1. Linear Granger Causality Test

\begin{tabular}{|c|c|c|c|}
\hline Dependent Variable & Independent Variable & $\chi^{2}(1)$ & $p$-value \\
\hline \multirow{7}{*}{ JUMPS } & $\begin{array}{c}\text { Consumers' Oil Price } \\
\text { Shocks }\end{array}$ & 0.0007 & 0.9783 \\
\cline { 2 - 4 } & $\begin{array}{c}\text { Economists' Oil Price } \\
\text { Shocks }\end{array}$ & 2.6810 & 0.1025 \\
\cline { 2 - 4 } & $\begin{array}{c}\text { Financial Market Oil } \\
\text { Price Shocks }\end{array}$ & 1.0236 & 0.3124 \\
\cline { 2 - 4 } & $\begin{array}{c}\text { Policymakers' Oil } \\
\text { Price Shocks }\end{array}$ & 2.0110 & 0.1571 \\
\hline
\end{tabular}

Note: The null hypothesis tests that the independent variable does not Granger cause JUMPS. 
Table 2. Brock et al., (1996, BDS) Test of Nonlinearity

\begin{tabular}{|c|c|c|c|c|c|}
\hline Independent & \multicolumn{5}{|c|}{$m$} \\
\cline { 2 - 6 } Variable & 2 & 3 & 4 & 5 & 6 \\
\hline $\begin{array}{c}\text { Consumers' } \\
\text { Oil Price } \\
\text { Shocks }\end{array}$ & $3.1950^{*}$ & $3.2720^{*}$ & $3.7610^{*}$ & $3.8310^{*}$ & $4.4140^{*}$ \\
\hline $\begin{array}{c}\text { Economists' } \\
\text { Oil Price } \\
\text { Shocks }\end{array}$ & $4.2950^{*}$ & $4.5490^{*}$ & $5.0070^{*}$ & $5.4830^{*}$ & $6.2360^{*}$ \\
\hline $\begin{array}{c}\text { Financial } \\
\text { Market Oil } \\
\text { Price Shocks }\end{array}$ & $3.725^{*}$ & $3.826^{*}$ & $4.237^{*}$ & $4.533^{*}$ & $5.243^{*}$ \\
\hline $\begin{array}{c}\text { Policymakers' } \\
\text { Oil Price } \\
\text { Shocks }\end{array}$ & $3.918^{*}$ & $4.030^{*}$ & $4.448^{*}$ & $4.868^{*}$ & $5.551^{*}$ \\
\hline
\end{tabular}

Note: Entries correspond to the z-statistic of the BDS test with the null of i.i.d. residuals, with the test applied to the residuals recovered from the jump equation with one lag each of JUMPS and the four different oil shocks considered in turn; * indicates rejection of the null hypothesis at 1 percent level of significance. 
Figure 1. Causality-in-Quantiles Test Results for S\&P500 Volatility Jumps due to Oil Shocks

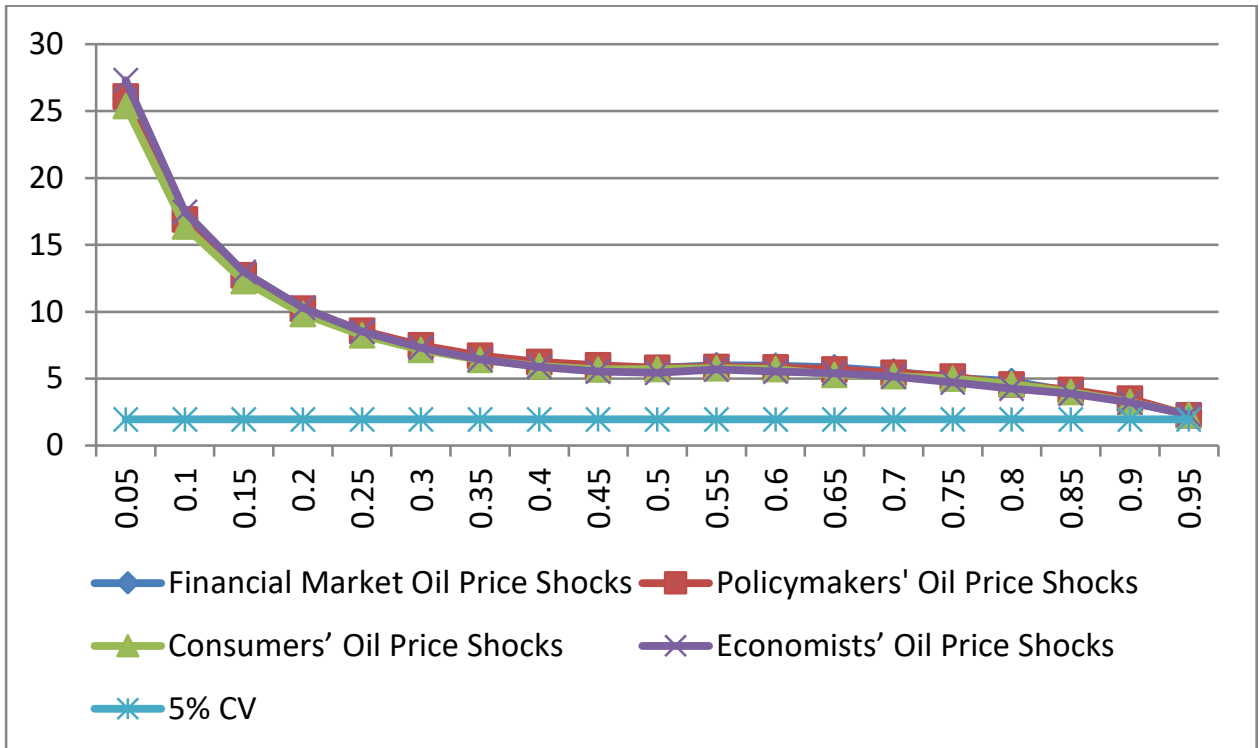

Notes: $\mathrm{CV}(5 \%)$ is the 5 percent critical value of 1.96. The horizontal axis measures the various quantiles, while the vertical axis captures the tests' statistic. The lines corresponding to consumers', economists', financial markets', and policymakers' oil price shocks show the rejection (non-rejection) of the null of no Granger causality from the various oil shocks to volatility jumps at the 5 percent level, if the lines are above (below) 1.96 for a specific quantile. 


\section{APPENDIX}

Table A1. Summary Statistics

\begin{tabular}{|c|c|c|c|c|c|}
\cline { 2 - 6 } \multicolumn{1}{c|}{} & \multicolumn{5}{c|}{ Variable } \\
\hline Statistic & $\begin{array}{c}\text { Financial Market Oil } \\
\text { Price Shocks }\end{array}$ & $\begin{array}{c}\text { Policymakers' Oil } \\
\text { Price Shocks }\end{array}$ & $\begin{array}{c}\text { Consumers' Oil } \\
\text { Price Shocks }\end{array}$ & $\begin{array}{c}\text { Economists' Oil } \\
\text { Price Shocks }\end{array}$ & JUMPS \\
\hline Mean & 0.9183 & -0.4323 & 0.4415 & -0.0016 & 0.0003 \\
\hline Median & -0.3333 & -0.7942 & 0.3827 & -0.9797 & 0.0000 \\
\hline Maximum & 36.1833 & 27.8137 & 16.6832 & 39.6887 & 0.0229 \\
\hline Minimum & -30.0989 & -46.6125 & -31.4363 & -31.7466 & 0.0000 \\
\hline Std. Dev. & 8.3352 & 8.2878 & 6.9725 & 8.4571 & 0.0014 \\
\hline Skewness & 0.8050 & -0.2617 & -0.3629 & 0.8581 & 14.6105 \\
\hline Kurtosis & 5.7207 & 6.1447 & 3.7549 & 6.0802 & 240.2552 \\
\hline Jarque-Bera & 134.9217 & 137.2027 & 14.8059 & 167.8413 & 771442.9000 \\
\hline$p$-value & 0.0000 & 0.0000 & 0.0006 & 0.0000 & 0.0000 \\
\hline Observations & \multicolumn{4}{|c|}{324} & \\
\hline
\end{tabular}

Note: Std. Dev: stands for standard deviation; $p$-value corresponds to the Jarque-Bera test with the null of normality. 
Figure A1. Data Plots

A1(a). S\&P500 Volatility Jumps

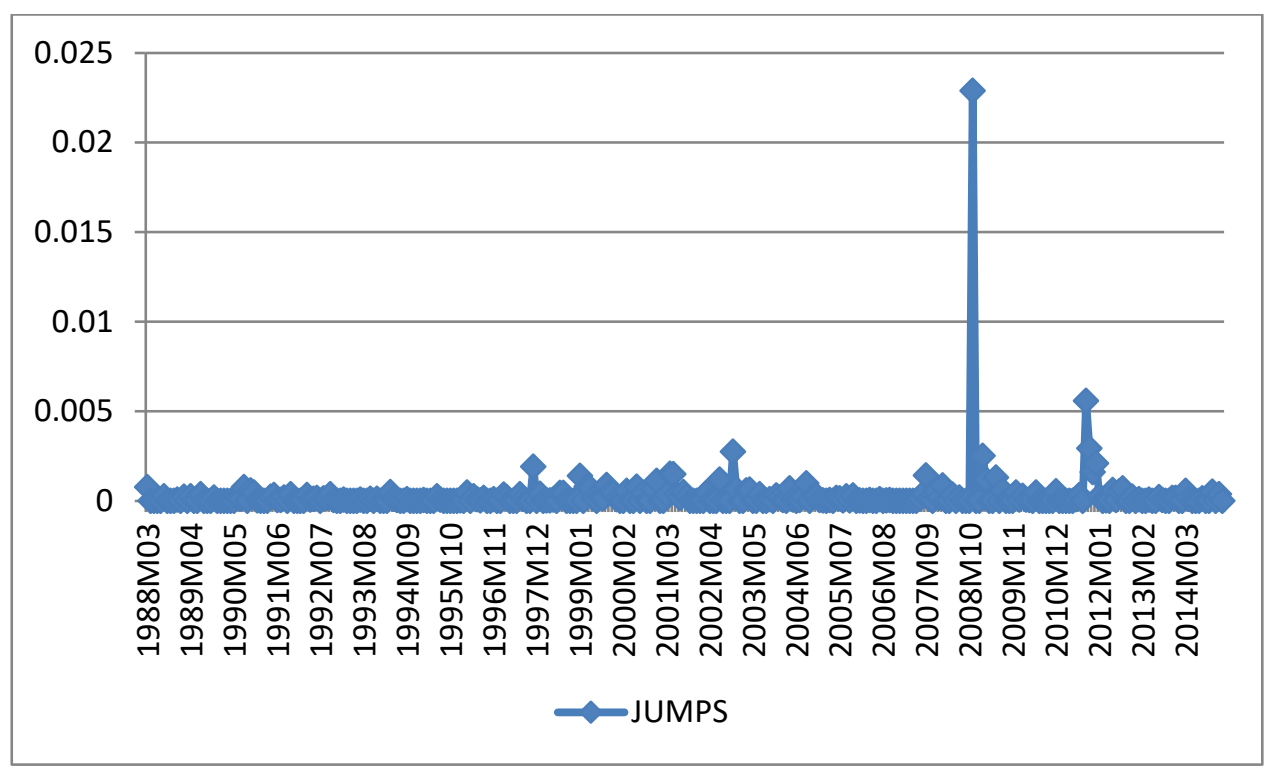

A1(b). Oil Price Shocks

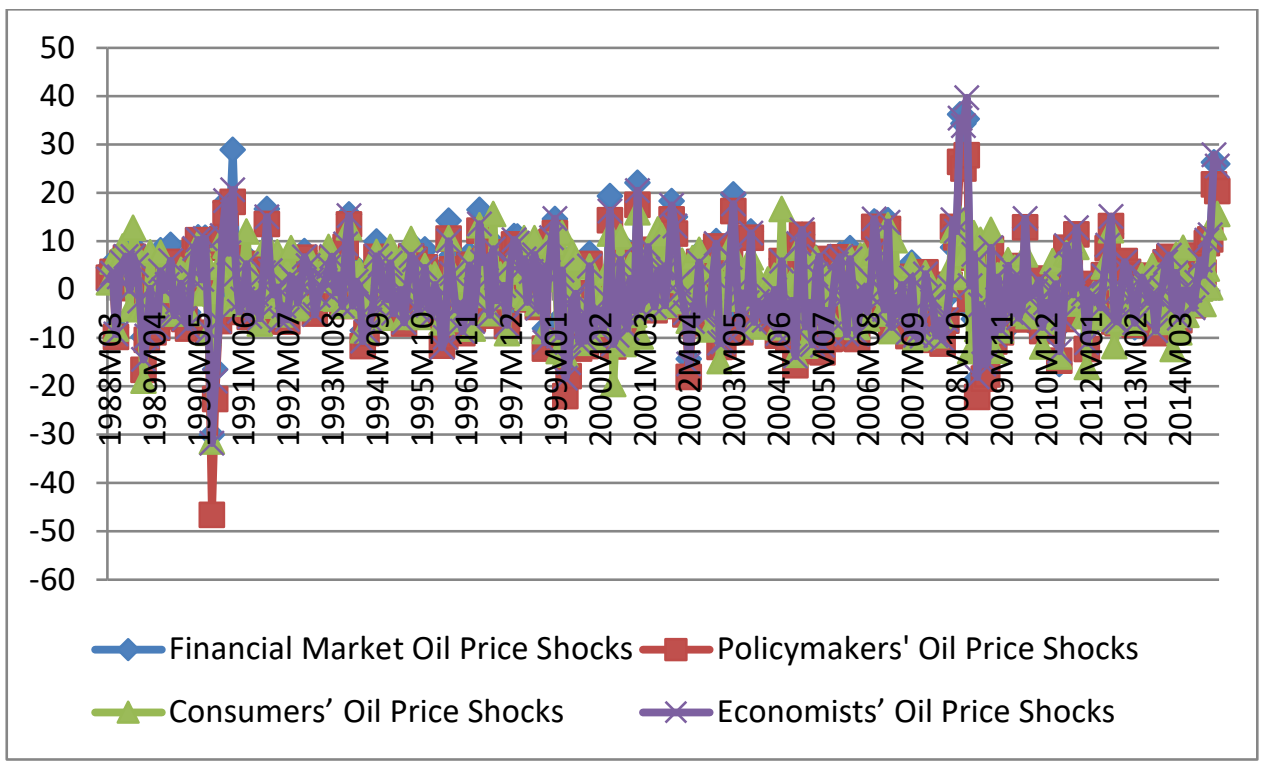


Figure A2. Cross-Quantilogram Results

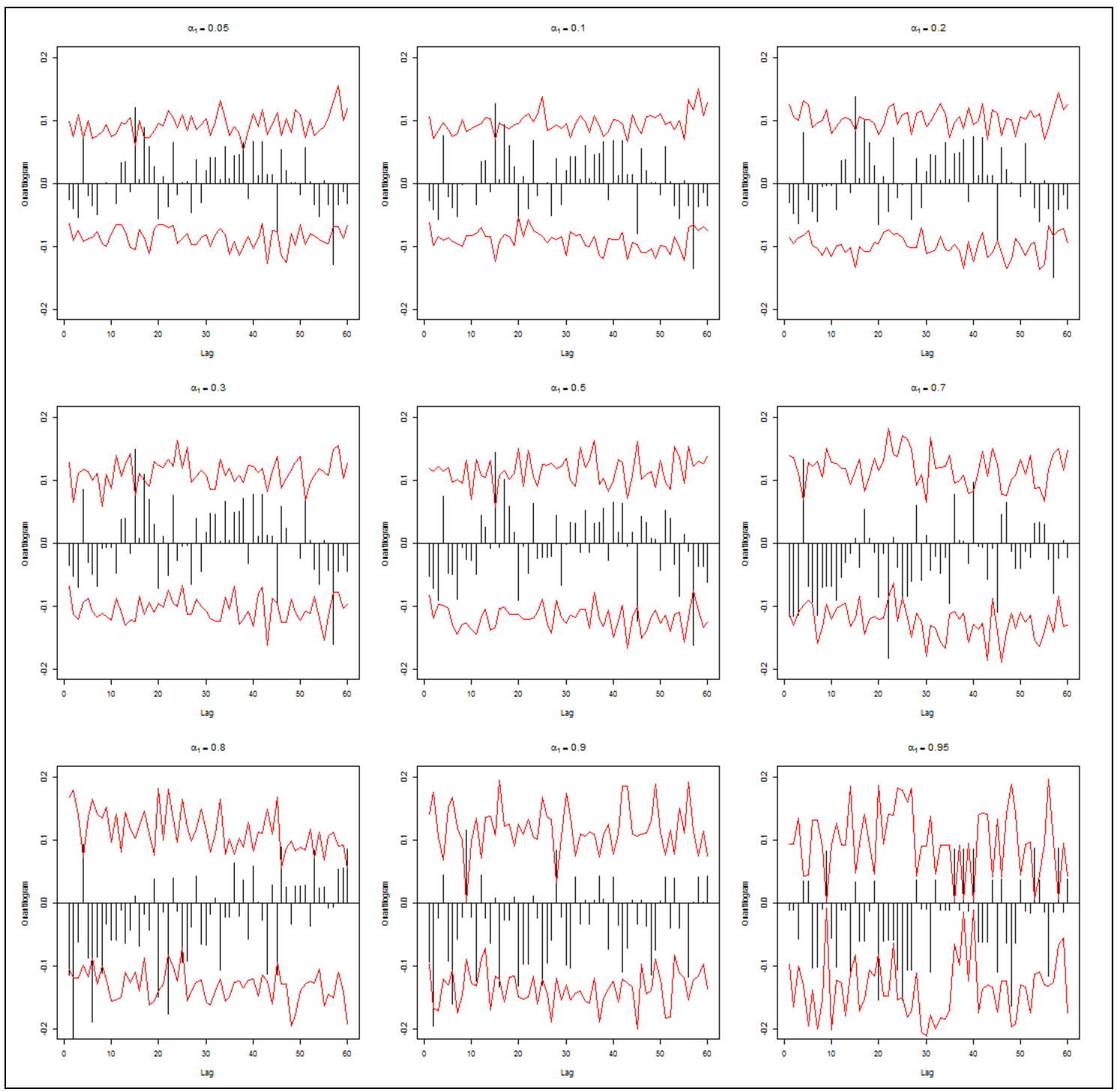

Figure A2(a): Sample cross-quantilograms for $\alpha_{2}=0.1$ to detect directional predictability from consumers' oil price shocks to JUMPS. Bar graphs describe sample cross-quantilograms and red lines are the $95 \%$ bootstrap confidence intervals for 2,000 bootstrap iterations. Note that $\alpha_{1}, \alpha_{2}$ correspond to the quantiles of JUMPS and oil shocks respectively. 


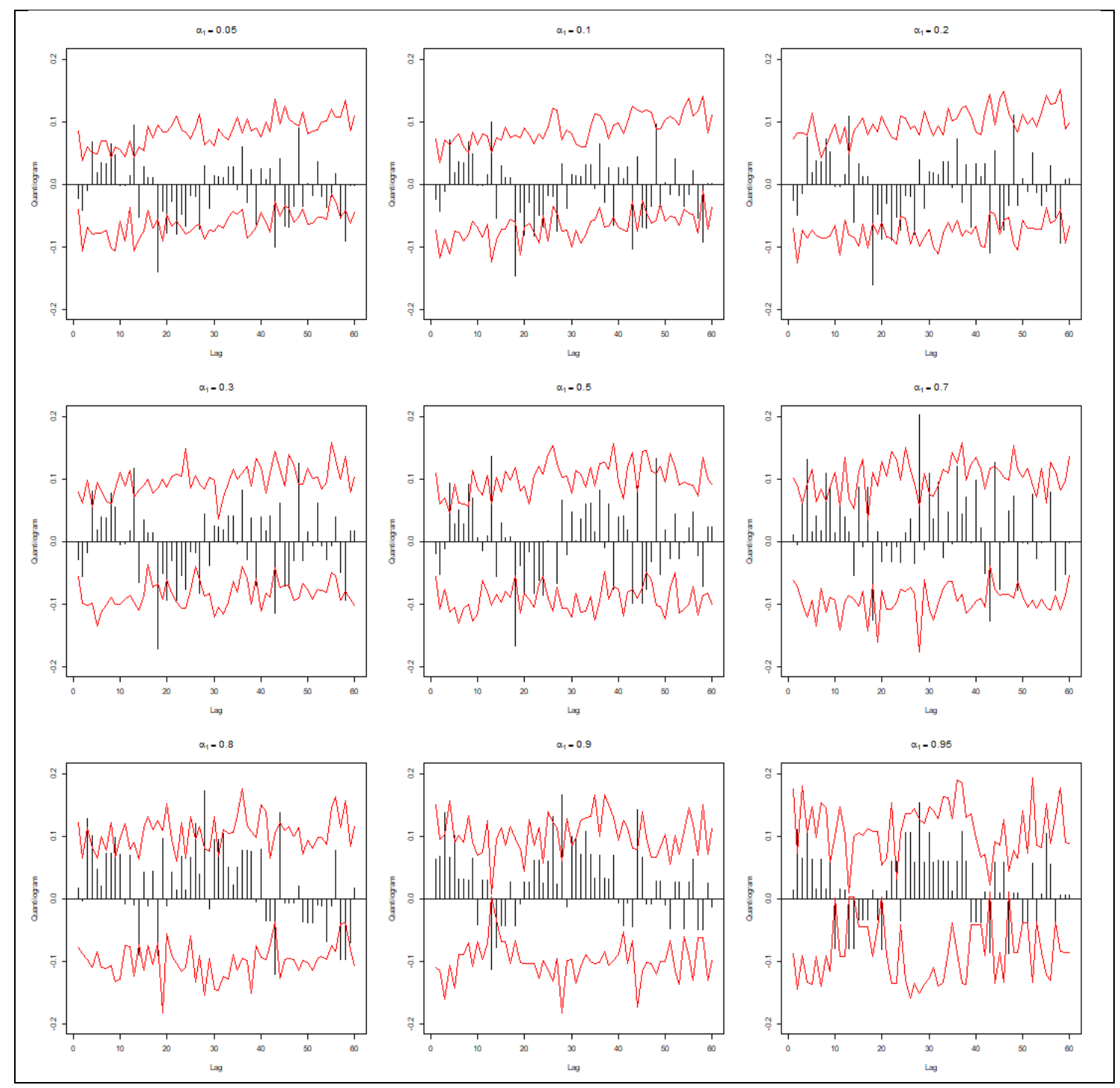

Figure A2(b): Sample cross-quantilograms for $\alpha_{2}=0.9$ to detect directional predictability from consumers' oil price shocks to JUMPS. Bar graphs describe sample cross-quantilograms and red lines are the 95\% bootstrap confidence intervals for 2,000 bootstrap iterations. Note that $\alpha_{1}, \alpha_{2}$ correspond to the quantiles of JUMPS and oil shocks respectively. 


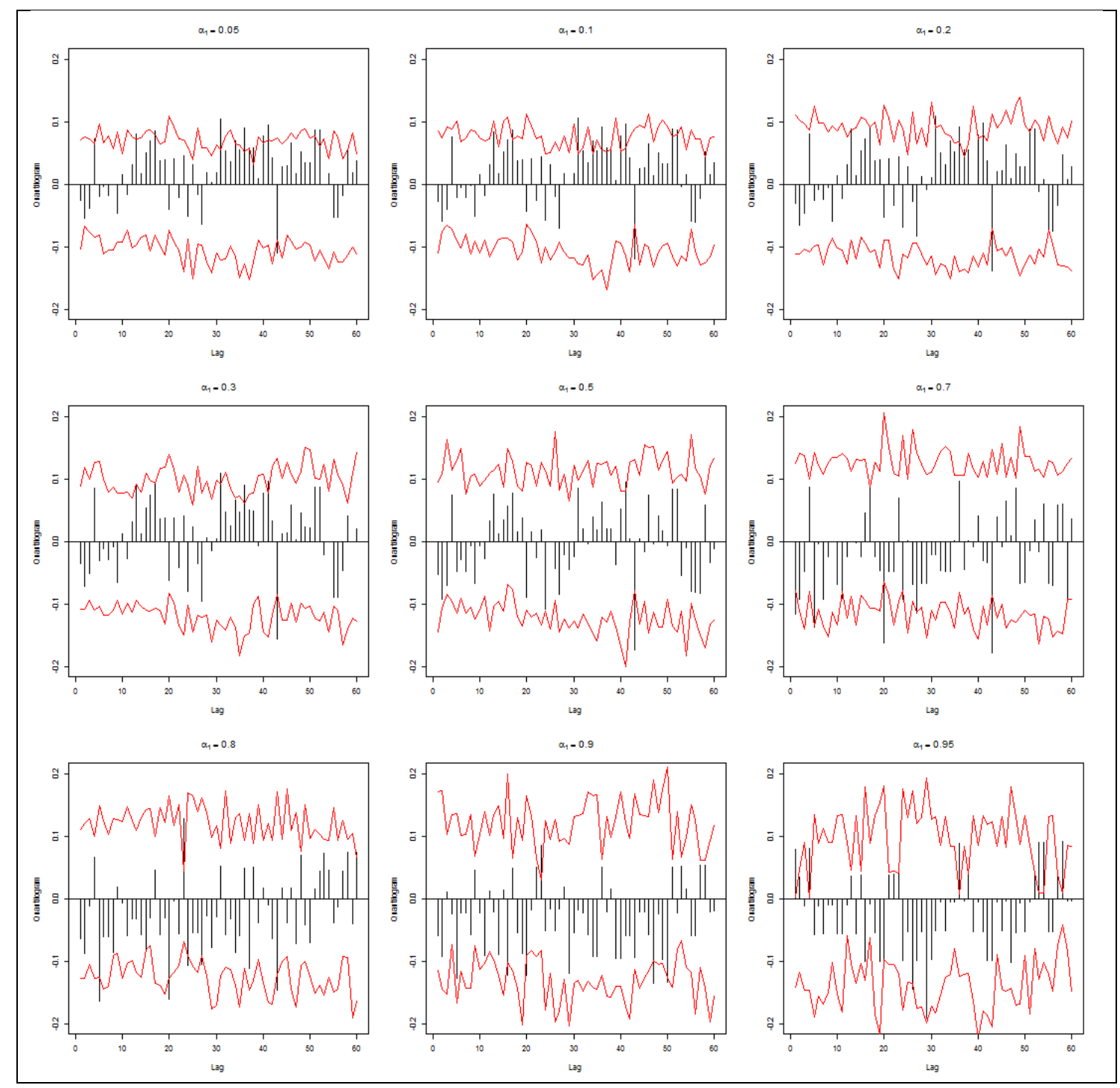

Figure A2(c): Sample cross-quantilograms for $\alpha_{2}=0.1$ to detect directional predictability from economists' oil price shocks to JUMPS. Bar graphs describe sample cross-quantilograms and red lines are the $95 \%$ bootstrap confidence intervals for 2,000 bootstrap iterations. Note that $\alpha_{1}, \alpha_{2}$ correspond to the quantiles of JUMPS and oil shocks respectively. 


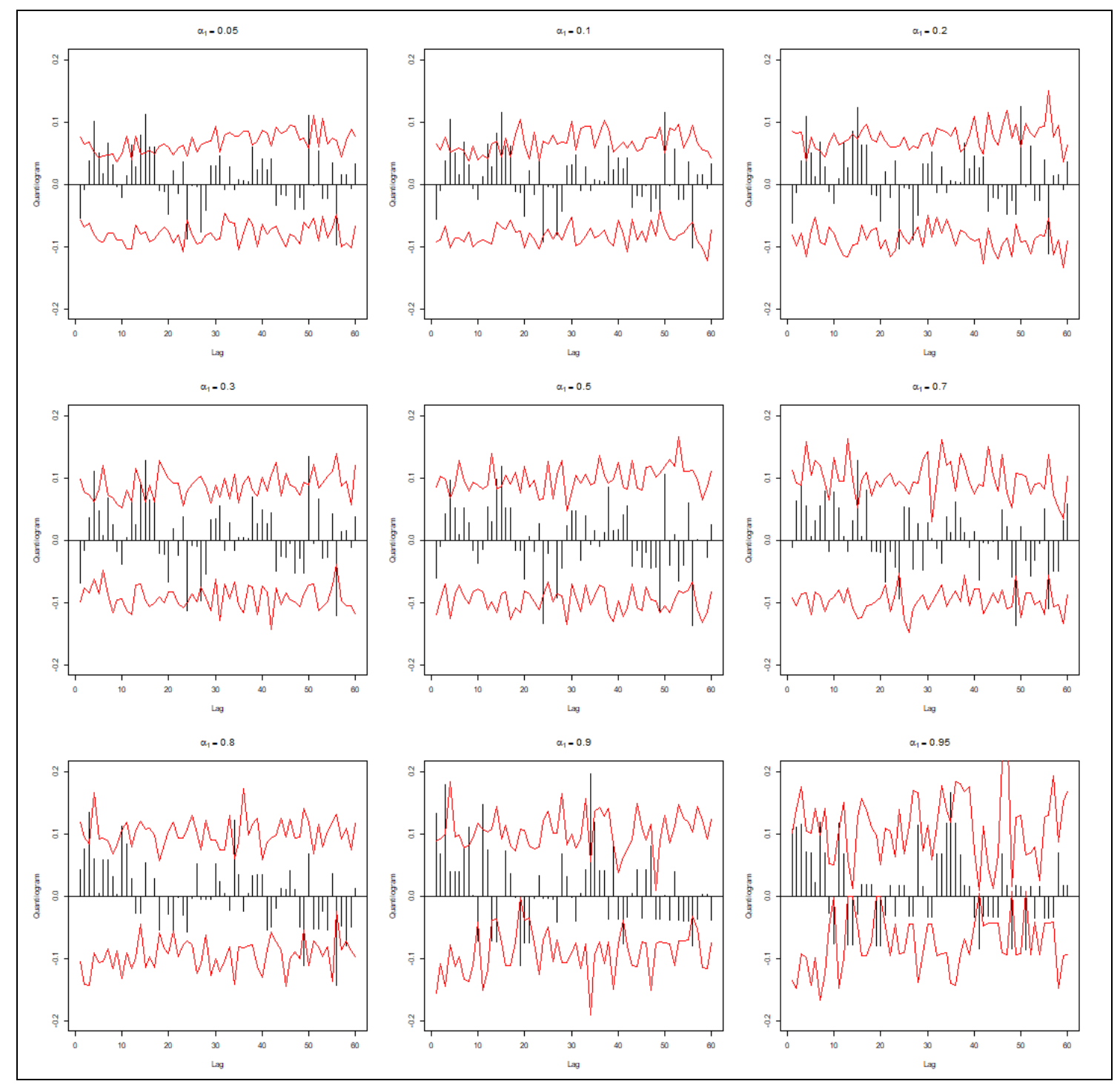

Figure A2(d): Sample cross-quantilograms for $\alpha_{2}=0.9$ to detect directional predictability from economists' oil price shocks to JUMPS. Bar graphs describe sample cross-quantilograms and red lines are the $95 \%$ bootstrap confidence intervals for 2,000 bootstrap iterations. Note that $\alpha_{1}, \alpha_{2}$ correspond to the quantiles of JUMPS and oil shocks respectively. 


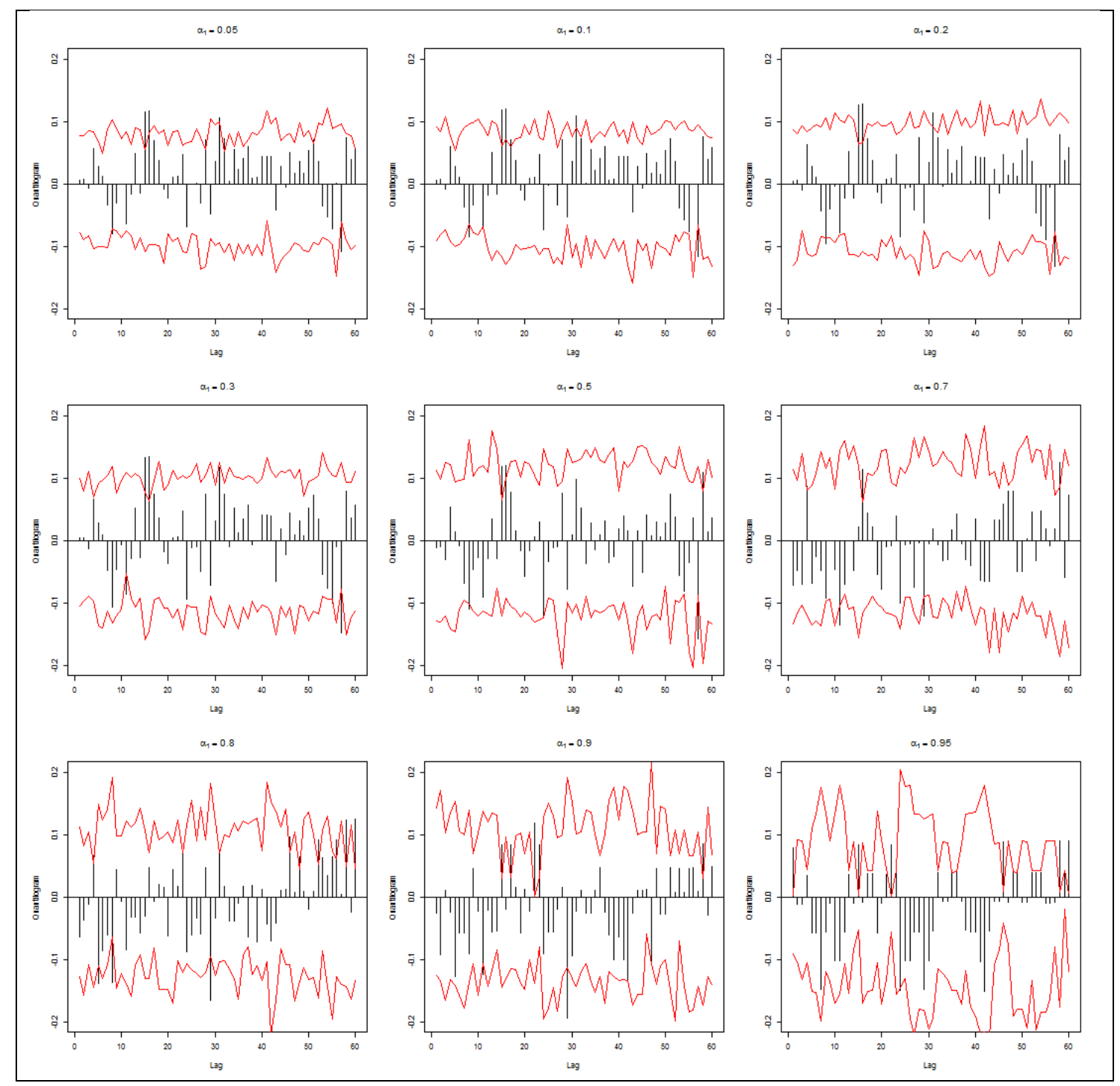

Figure A2(e): Sample cross-quantilograms for $\alpha_{2}=0.1$ to detect directional predictability from financial market's oil price shocks to JUMPS. Bar graphs describe sample cross-quantilograms and red lines are the 95\% bootstrap confidence intervals for 2,000 bootstrap iterations. Note that $\alpha_{1}, \alpha_{2}$ correspond to the quantiles of JUMPS and oil shocks respectively. 


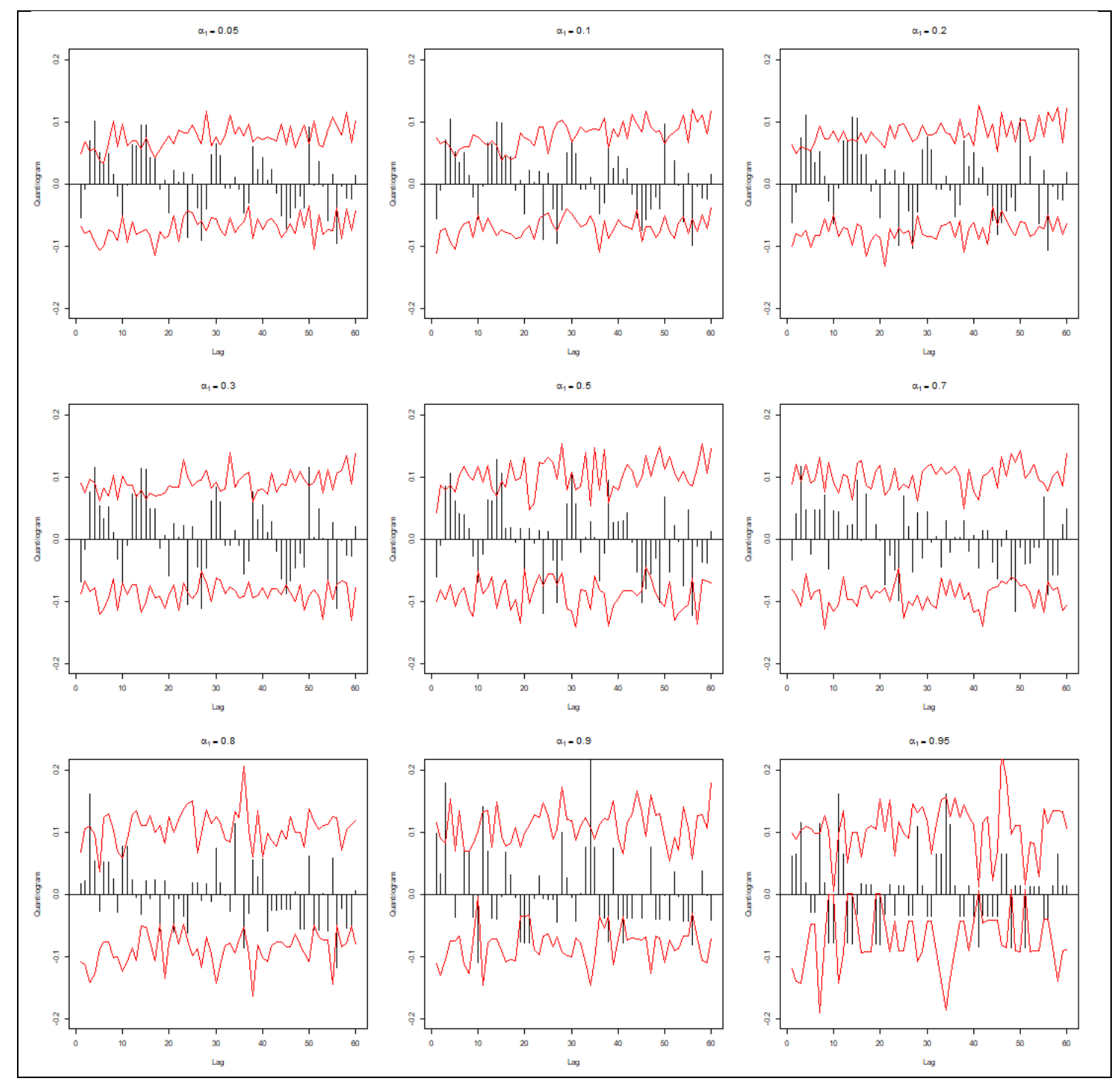

Figure A2(f): Sample cross-quantilograms for $\alpha_{2}=0.9$ to detect directional predictability from financial market's oil price shocks to JUMPS. Bar graphs describe sample cross-quantilograms and red lines are the $95 \%$ bootstrap confidence intervals for 2,000 bootstrap iterations. Note that $\alpha_{1}, \alpha_{2}$ correspond to the quantiles of JUMPS and oil shocks respectively. 


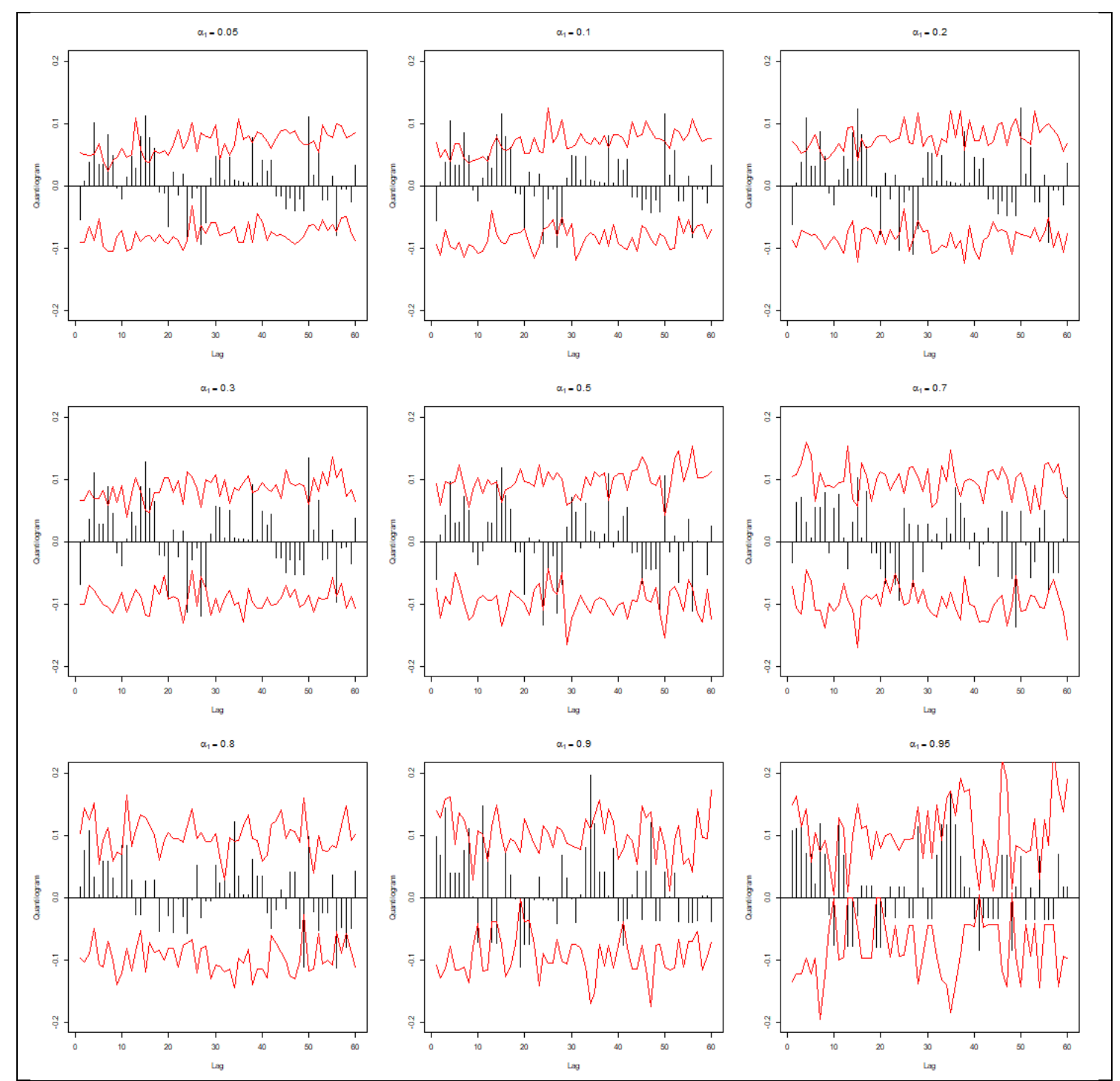

Figure A2(g): Sample cross-quantilograms for $\alpha_{2}=0.1$ to detect directional predictability from policymakers' oil price shocks to JUMPS. Bar graphs describe sample cross-quantilograms and red lines are the $95 \%$ bootstrap confidence intervals for 2,000 bootstrap iterations. Note that $\alpha_{1}, \alpha_{2}$ correspond to the quantiles of JUMPS and oil shocks respectively. 


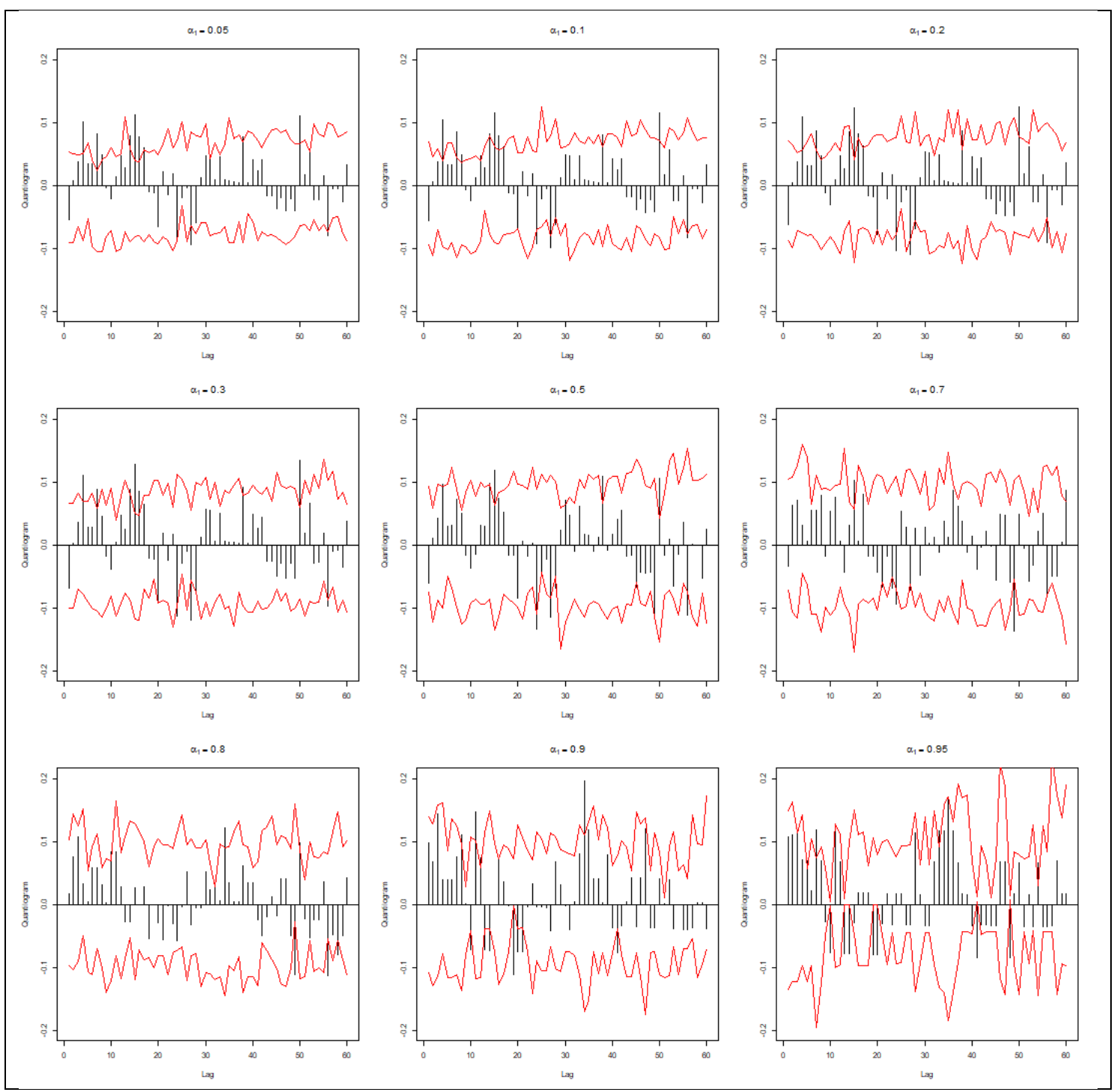

Figure A2(h): Sample cross-quantilograms for $\alpha_{2}=0.9$ to detect directional predictability from policymakers' oil price shocks to JUMPS. Bar graphs describe sample cross-quantilograms and red lines are the $95 \%$ bootstrap confidence intervals for 2,000 bootstrap iterations. Note that $\alpha_{1}, \alpha_{2}$ correspond to the quantiles of JUMPS and oil shocks respectively. 
Table A2. Causality-in-Quantiles Test Results for S\&P500 Volatility Jumps due to Positive and Negative Oil Shocks

\begin{tabular}{|c|c|c|c|c|c|c|c|c|c|c|c|c|c|c|c|c|c|c|c|}
\hline \multirow[t]{2}{*}{ Variable } & \multicolumn{19}{|c|}{ Quantile } \\
\hline & \begin{tabular}{|l|}
0.05 \\
\end{tabular} & 0.1 & 0.15 & 0.2 & \begin{tabular}{|l|}
0.25 \\
\end{tabular} & 0.3 & 0.35 & 0.4 & 0.45 & 0.5 & 0.55 & 0.6 & 0.65 & 0.7 & \begin{tabular}{|l|}
0.75 \\
\end{tabular} & 0.8 & 0.85 & 0.9 & 0.95 \\
\hline Cons. $(+)$ & 50.15* & $28.52 *$ & 18.21* & 11.89* & $7.65^{*}$ & $4.74 *$ & $2.79 *$ & 1.61 & 1.09 & 1.15 & 1.18 & 1.10 & 1.44 & 1.36 & 1.70 & 1.45 & 1.18 & 1.13 & 0.38 \\
\hline Cons.(-) & 65.53* & $38.42 *$ & $25.51 *$ & $17.50^{*}$ & $12.00^{*}$ & $8.05^{*}$ & $5.19^{*}$ & $3.18^{*}$ & 1.87 & 1.38 & 1.36 & 1.11 & 1.09 & 1.07 & 1.05 & 1.16 & 1.22 & 0.62 & 0.46 \\
\hline Econ. $(+)$ & 51.33* & $28.71 *$ & $17.97 *$ & $11.43 *$ & 7.09* & $4.18^{*}$ & $2.30^{*}$ & 1.27 & 0.97 & 1.00 & 0.97 & 1.18 & 1.60 & 1.47 & 1.75 & 1.40 & 1.11 & 0.96 & 0.32 \\
\hline Econ.(-) & 66.89* & $39.94 *$ & $27.15^{*}$ & 19.19* & $13.68^{*}$ & $9.66^{*}$ & $6.68^{*}$ & $4.49 *$ & $2.95^{*}$ & 1.92 & 1.92 & 1.40 & 1.41 & 1.15 & 1.10 & 1.19 & 1.34 & 0.73 & 0.54 \\
\hline $\mathrm{FM}(+)$ & 48.34* & $27.22 *$ & $17.17 *$ & 11.04* & $6.97 *$ & $4.22 *$ & $2.44^{*}$ & 1.45 & 1.13 & 1.27 & 1.20 & 1.54 & $2.00^{*}$ & 1.73 & 1.70 & 1.48 & 1.05 & 1.00 & 0.37 \\
\hline $\mathrm{FM}(-)$ & $67.67 *$ & $40.06^{*}$ & $26.90 *$ & 18.73* & 13.09* & $9.01 *$ & $6.03^{*}$ & $3.88^{*}$ & $2.44^{*}$ & 1.84 & 1.95 & 1.32 & 1.33 & 1.10 & 1.00 & 1.12 & 1.34 & 0.63 & 0.45 \\
\hline $\mathrm{PM}(+)$ & $47.48^{*}$ & $26.42^{*}$ & $16.42^{*}$ & $10.36^{*}$ & $6.36^{*}$ & $3.71 *$ & $2.04^{*}$ & 1.17 & 1.02 & 1.13 & 1.02 & 1.37 & 1.82 & 1.65 & $1.98^{*}$ & 1.57 & 1.22 & 1.06 & 0.34 \\
\hline $\operatorname{PM}(-)$ & 69.97* & $41.85^{*}$ & $28.46^{*}$ & $20.13 *$ & $14.35^{*}$ & $10.14 *$ & 7.01* & $4.71^{*}$ & $3.08^{*}$ & $2.07 *$ & $2.01 *$ & 1.43 & 1.47 & 1.20 & 1.14 & 1.11 & 1.23 & 0.74 & 0.49 \\
\hline
\end{tabular}

is positive or negative; ${ }^{*}$ indicates significance at the 5 percent level. 
Table A3. Causality-in-Quantiles Test Results for S\&P500 Volatility Jumps due to Financial Market's Oil Shocks at Various Forecast Horizons

\begin{tabular}{|c|c|c|c|c|c|c|c|c|c|c|c|c|c|c|c|c|c|c|c|}
\hline \multirow[t]{2}{*}{ Variable } & \multicolumn{19}{|c|}{ Quantile } \\
\hline & 0.05 & .1 & 0.15 & 0.2 & 0.25 & 0.3 & 0.35 & 0.4 & 0.45 & 0.5 & 0.55 & 0.6 & 0.65 & 0.7 & 0.75 & 0.8 & 0.85 & 0.9 & 0.95 \\
\hline $3 \mathrm{M}$ & $23.86^{*}$ & $5.41 *$ & $.58^{*}$ & 9.31* & 7.81* & $6.80^{*}$ & $6.13^{*}$ & $5.71 *$ & $5.52^{*}$ & & $5.72^{*}$ & $5.46^{*}$ & $5.48^{*}$ & $5.14^{*}$ & $4.95^{*}$ & $4.47 *$ & $3.83^{*}$ & $3.23 *$ & $2.22^{*}$ \\
\hline $3 \mathrm{M}(+$ & $.05^{*}$ & $29.86^{*}$ & & $12.88^{*}$ & $8.51^{*}$ & $5.46^{*}$ & & & & & 1.59 & 1.21 & 1.16 & 1.05 & 0.92 & .97 & 0.68 & 64 & 41 \\
\hline $3 \mathrm{M}$ & $.07^{*}$ & $8.16^{*}$ & $13^{*}$ & $6.92^{*}$ & $4.22^{*}$ & $2.49 *$ & 1.51 & 1.13 & 1. & & 1.52 & $2.12^{*}$ & $2.31 *$ & $2.44^{*}$ & $2.25^{*}$ & 1.58 & $.97 *$ & .76 & 44 \\
\hline $6 \mathrm{M}$ & $.78^{*}$ & $15.68^{*}$ & $12.00 *$ & $9.81 *$ & $8.38^{*}$ & $7.41 *$ & $6.75^{*}$ & $6.34 *$ & $6.14^{*}$ & 3* & $6.09 *$ & $5.99 *$ & $5.83^{*}$ & $5.59 *$ & $5.26^{*}$ & $4.85^{*}$ & $4.30^{*}$ & $3.68^{*}$ & $2.50^{*}$ \\
\hline $6 \mathrm{M}(+)$ & $2.95^{*}$ & $30.72^{*}$ & $20.08^{*}$ & $13.49^{*}$ & $9.00^{*}$ & $5.83^{*}$ & $3.60^{*}$ & $2.13^{*}$ & 1.29 & 1.32 & 1.52 & 1.12 & 0.98 & 1.01 & 0.91 & 0.85 & 0.71 & 0.61 & 0.42 \\
\hline $6 \mathrm{M}(-)$ & 29.14* & $16.17 *$ & $10.02 *$ & 6.34* & $3.98^{*}$ & $2.49 *$ & 1.65 & 1.36 & 1.55 & 1.74 & 1.75 & $2.59 *$ & $2.29 *$ & $2.66^{*}$ & $2.72 *$ & 2.39* & $2.07 *$ & 1.79 & 0.53 \\
\hline $9 \mathrm{M}$ & $24.88^{*}$ & 16.04* & $12.04^{*}$ & $9.66^{*}$ & $8.09 *$ & $7.02 *$ & $6.30^{*}$ & $5.85^{*}$ & $5.62^{*}$ & $5.62^{*}$ & $5.72^{*}$ & $5.68^{*}$ & $5.44^{*}$ & $5.21 *$ & $5.11 *$ & $4.66^{*}$ & 4.05* & $3.14^{*}$ & $2.24 *$ \\
\hline $9 \mathrm{M}($ & $53.46^{*}$ & $30.52^{*}$ & $19.67^{*}$ & $13.02^{*}$ & $8.54^{*}$ & $5.42 *$ & $3.27 *$ & 1.90 & 1.1 & 1.1 & 1.26 & 1.10 & 1.05 & 0.95 & 0.89 & 1.08 & 0.76 & 0.60 & 0.42 \\
\hline $9 \mathrm{M}$ & $35.89 *$ & $20.06^{*}$ & $57 *$ & $8.04 *$ & $5.06^{*}$ & $3.09 *$ & 1.86 & & & & 1.30 & 1.68 & $2.23^{*}$ & $2.30^{*}$ & 2.03* & 1.53 & 1.52 & 1.57 & 0.50 \\
\hline $12 \mathrm{M}$ & $54.98^{*}$ & $31.85^{*}$ & $20.87^{*}$ & $14.10^{*}$ & $9.48^{*}$ & $6.22 *$ & $3.91 *$ & $2.35^{*}$ & 1.43 & 1.30 & 1.37 & 1.11 & 1.03 & 1.00 & 0.93 & 1.03 & 0.79 & 0.61 & 0.45 \\
\hline $12 \mathrm{M}(+)$ & $54.98^{*}$ & $31.85^{*}$ & $20.87^{*}$ & $14.10^{*}$ & $9.48^{*}$ & $6.22 *$ & $3.91 *$ & $2.35^{*}$ & 1.43 & 1.30 & 1.37 & 1.11 & 1.03 & 1.00 & 0.93 & 1.03 & 0.79 & 0.61 & 0.45 \\
\hline $12 \mathrm{M}(-)$ & $32.27 *$ & $17.78^{*}$ & $10.93^{*}$ & 6.83* & 4.19* & $2.52^{*}$ & 1.56 & 1.19 & 1.36 & 1.32 & 1.42 & 1.90 & $1.97 *$ & $2.34^{*}$ & 2.04* & 1.67 & 1.41 & 1.46 & 0.50 \\
\hline
\end{tabular}

Note: 3M, 6M, 9M and 12M stands for financial market's oil price shock at horizon of 3-month, 6-month, 9-month, and 12-month-ahead respectively; $(+)$ or (-) indicate whether the shock is positive or negative; $*$ indicates significance at the 5 percent level. 